\title{
An Ofloxacin-Induced Anaphylaxis through an IgG4-Mediated but Not IgE-Mediated Basophil Activation Mechanism
}

\author{
Ji Hye Kim ${ }^{1}$, Dae-Hong Seo ${ }^{2}$, Ga-Young Ban ${ }^{3}$, Eun-Mi Yang ${ }^{3}$, Yoo Seob Shin ${ }^{3}$, Young-Min Ye ${ }^{3}$, and Hae-Sim Park ${ }^{3}$ \\ 'Division of Pulmonology and Allergy, Konyang University Hospital, Konyang University College of Medicine, Daejeon; '2Division of Allergy and Pulmonology, Chungmu Hospital, \\ Cheonan; ${ }^{3}$ Department of Allergy and Clinical Immunology, Ajou University School of Medicine, Suwon, Korea
}

\section{Dear Editor:}

We report a case of 20-year-old female patient with ofloxacin-induced anaphylaxis mediated by IgG4 antibody.

One of second-generation fluoroquinolone, ofloxacin is prescribed widely to treat bacterial infections. Reports of serious hypersensitivity reactions to quinolone are increasing due to high consumption worldwide [1].

The pathogenesis of anaphylaxis caused by ofloxacin is not yet fully understood, as it is not commonly reported. There has been a report demonstrating high serum specific IgE levels to ofloxacin-human serum albumin (HSA) conjugate using enzymelinked immunosorbent assay (ELISA), enzyme-linked immunospecific assay [2]; however, this is the first report to suggest an IgG4-mediated but not IgE-mediated mechanism in a patient with ofloxacin-induced anaphylaxis.

A 20-year-old female with allergic rhinitis was referred to our department for the evaluation of anaphylaxis because she had experienced generalized urticaria and dyspnea with wheezing, and hoarseness within 1 hour after oral ingestion of ofloxacin $100 \mathrm{mg}$. It was her first ingestion of ofloxacin. The patient had a history of acute, generalized urticaria and drug allergy to nonsteroidal anti-inflammatory drugs. Her mother had a history of bronchial asthma. At the initial visit, no abnormal findings were noted on physical examination and radiography/spirometry results. Her serum total IgE level was $42 \mathrm{kU} / \mathrm{L}$. Allergy skin prick tests showed positive responses to Dermatophagoides farinae and D. pteronyssinus, but negative responses to ofloxacin at concentrations of $0.1-10 \mathrm{mg} / \mathrm{ml}$, with a positive control being a mean wheal size of $4 \mathrm{~mm}$ to histamine.

Ofloxacin-HSA conjugate was conducted to investigate immunologic mechanisms to detect serum specific IgE antibody to ofloxacin-HSA conjugate using ELISA as

\author{
Received on February 14, 2017 \\ Revised on April 20, 2017 \\ Accepted on April 21, 2017 \\ Hae-Sim Park \\ Department of Allergy and Clinical \\ Immunology, Ajou University School of \\ Medicine, 206 World cup-ro, Yeongtong- \\ gu, Suwon 16499, Korea \\ Tel: +82-31-219-5196 \\ Fax: +82-31-219-5154 \\ E-mail: hspark@ajou.ac.kr
}

*No potential conflict of interest relevant to this article was reported. 
previously described [2]. When the positive cutoff value was determined from the mean +3 standard deviation

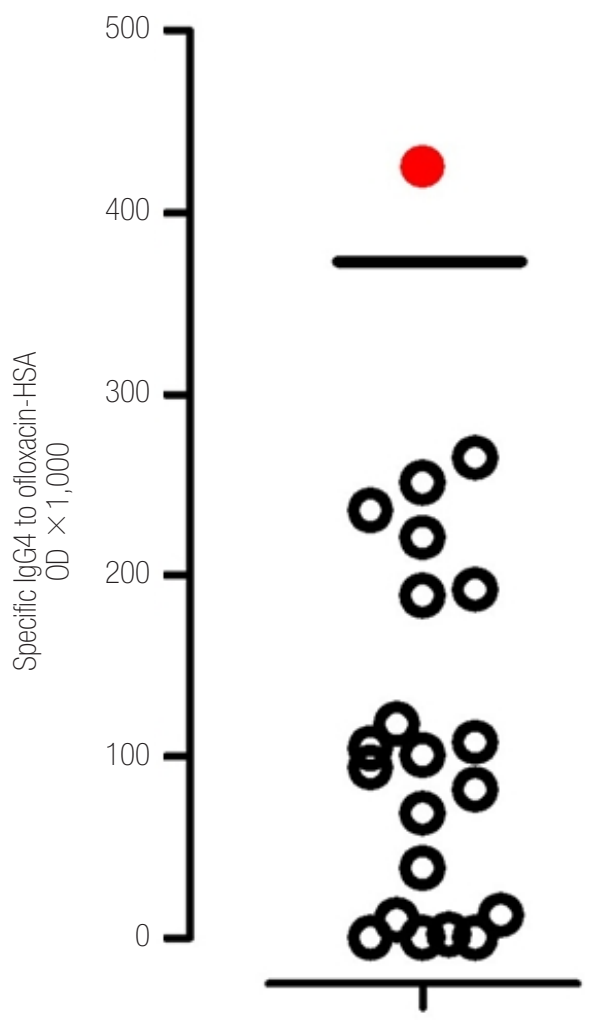

Figure 1. Detection of serum specific IgG4 antibodies to ofloxacinhuman serum albumin (HSA) conjugate by ELISA from the patient (O) and 20 non-atopic normal controls (O). OD: optical density; ELISA: enzyme-linked immunosorbent assay.

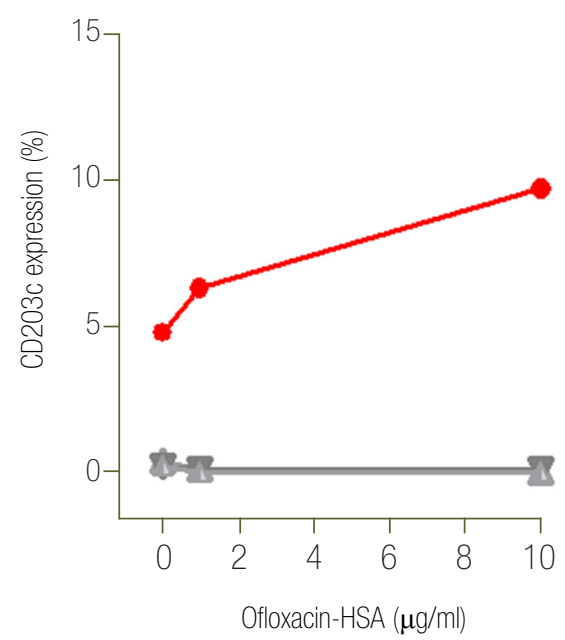

absorbance values of 20 nonatopic healthy controls that never experienced any other drug allergy according to medical records, serum specific IgE antibody was not detected in the patient's serum, while high serum specific IgG4 antibody was detected as shown in Figure 1. A basophil activation test (BAT) was done with addition of ofloxacin and anti-IgG4 antibody using peripheral basophils from the patient and three healthy controls to confirm specific IgG4-mediated mechanisms. A significant upregulation of CD203c, a marker of activated basophils, was noted with serial additions of ofloxacin-HSA (from $6.35 \%$ to $9.7 \%$ ), while no changes were noted in three healthy controls (Figure 2).

Until now, anaphylaxis cases caused by ciprofloxacin, one of the most frequently prescribed oral fluoroquinolones in the U.S. and worldwide, have occasionally been reported $[3,4]$. The frequency of ofloxacin prescription as an alternative therapy is expected to increase due to a high incidence of drug-resistant tuberculosis in Asia.

Until now, immediate reactions such as urticaria and anaphylaxis were reported as a phenotype of hypersensitivity reactions to quinolone, although frequencies have been reported to be less than 2\% [1]. An IgE-mediated reaction is known as a major pathogenetic mechanism of immediate hypersensitivity to quinolone. Using sepharoseradioimmunoassay for the determination of specific IgE

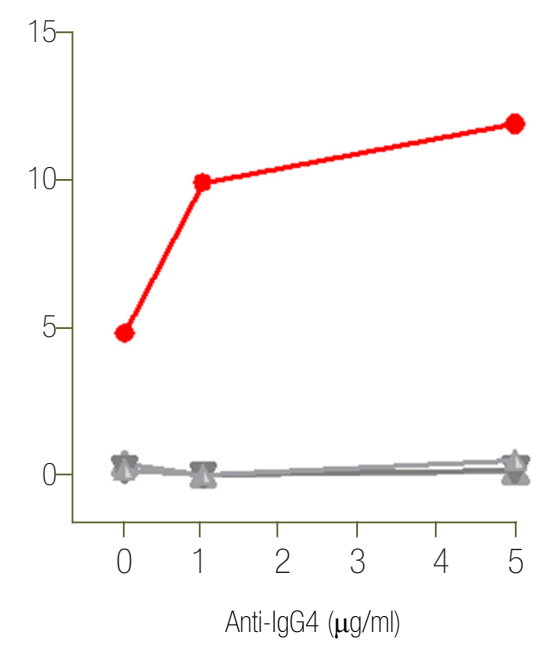

Figure 2. Results of basophil activation test with addition of ofloxacin-human serum albumin (HSA) conjugate (A) and anti-lgG4 antibodies $(\mathrm{B})$ in the patient $(\bullet)$ and three healthy controls $(\diamond, \triangle, \nabla)$. 
in the serum, a previous study reported an IgE-mediated mechanism in 12 of $38(31.5 \%)$ patients with anaphylaxis and urticaria as well as serum specific IgE to ciprofloxacin, moxifloxacin, and levofloxacin [5]. Another study showed in 30 of 55 (54.5\%) patients with immediate reactions to eight quinolones including ofloxacin detected by serum specific IgE [6]. In cases of ofloxacin-induced anaphylaxis, our previous study reported four of five (80\%) patients with serum specific IgE to ofloxacin-HSA conjugate using ELISA [2].

Previous studies have suggested involvement of non- $\operatorname{IgE}$ mediated mechanisms in patients with quinolone-induced immediate hypersensitivity reactions [1,7]. Nam et al. [8] reported one patient with cefotetan-induced anaphylaxis that was mediated by IgG antibody. The non-IgE mediated mechanisms of anaphylaxis are not well understood in cases of quinolone-induced anaphylaxis. Since IgG-mediated immediate anaphylaxis through the low-affinity $\operatorname{IgG}$ receptor Fc $\gamma$-receptor was introduced in a murine model [9], IgG-mediated alternative pathways are suggested, as basophil to release platelet-activating factor upon stimulation with allergen-IgG complexes [10]. It is possible that alternative pathways could be mediated by basophils, IgG, IgG receptor, and platelet-activating factor, particularly a high level of serum IgG, but not specific IgE to relevant allergens. The BAT is a useful diagnostic method for immediate-type drug allergy based upon different activation markers, being mostly CD203c and CD63 involving IgE-dependent and IgE-independent basophil-mediated reactions [11-13]. The sensitivity of the BAT to quinolone has recently been reported to $71.1 \%$ [5]. In the present study, we presumed that specific IgG4 antibody may play a role in the activation of basophil as a significant mediator through an alternative mechanism in that there were a high serum specific IgG4 and no serum specific IgE to ofloxacin-HSA conjugate and a significant upregulation of basophils in response to ofloxacin and anti-IgG4 antibody.

Anaphylaxis is a serious reaction that may lead to death and prompt management is crucial [14]. The mainstay of anaphylaxis treatment is to restore and maintain vital signs by early administration of intramuscular epinephrine along with antihistamine and corticosteroid. Regardless of allergen or mechanism of anaphylaxis, mast cell and basophil are activated to commence and amplify allergic reactions, and release various inflammatory mediators such as tryptase and histamine to cause anaphylaxis reactions [15].

In conclusion, this is a case of ofloxacin-induced anaphylaxis through an IgG4-mediated but not IgE-medicated basophil activation mechanism.

\section{ORCID}

Ji Hye Kim http://orcid.org/0000-0003-4677-0513

Ga-Young Ban http://orcid.org/0000-0002-7961-742X

Yoo Seob Shin http://orcid.org/0000-0002-9855-3185

Young-Min Ye http://orcid.org/0000-0002-7517-1715

Hae-Sim Park http://orcid.org/0000-0003-2614-0303

\section{References}

1. Blanca-López N, Andreu I, Torres Jaén MJ. Hypersensitivity reactions to quinolones. Curr Opin Allergy Clin Immunol 2011;11:285-91.

2. Nam YH, Kim JE, Kim SH, Jin HJ, Hwang EK, Shin YS, et al. Immunologic evaluation of ofloxacin hypersensitivity. Allergy Asthma Immunol Res 2012;4:367-9.

3. Hicks LA, Bartoces MG, Roberts RM, Suda KJ, Hunkler RJ, Taylor TH Jr, et al. US outpatient antibiotic prescribing variation according to geography, patient population, and provider specialty in 2011. Clin Infect Dis 2015;60:1308-16.

4. Jones SC, Budnitz DS, Sorbello A, Mehta H. USbased emergency department visits for fluoroquinolone-associated hypersensitivity reactions. Pharmacoepidemiol Drug Saf 2013;22:1099-106.

5. Aranda A, Mayorga C, Ariza A, Doña I, Rosado A, Blanca-Lopez N, et al. In vitro evaluation of IgEmediated hypersensitivity reactions to quinolones. Allergy 2011;66:247-54.

6. Manfredi M, Severino M, Testi S, Macchia D, Ermini 
G, Pichler WJ, et al. Detection of specific IgE to quinolones. J Allergy Clin Immunol 2004;113:155-60.

7. Lobera T, Audícana MT, Alarcón E, Longo N, Navarro B, Muñoz D. Allergy to quinolones: low crossreactivity to levofloxacin. J Investig Allergol Clin Immunol 2010;20:607-11.

8. Nam YH, Hwang EK, Ban GY, Jin HJ, Yoo HS, Shin YS, et al. Immunologic evaluation of patients with cefotetan-induced anaphylaxis. Allergy Asthma Immunol Res 2015;7:301-3.

9. Finkelman FD. Anaphylaxis: lessons from mouse models. J Allergy Clin Immunol 2007;120:506-15.

10. Tsujimura Y, Obata K, Mukai K, Shindou H, Yoshida M, Nishikado H, et al. Basophils play a pivotal role in immunoglobulin-G-mediated but not immunoglobulin-E-mediated systemic anaphylaxis. Immunity 2008;28:581-9.
11. Gómez E, Torres MJ, Mayorga C, Blanca M. Immunologic evaluation of drug allergy. Allergy Asthma Immunol Res 2012;4:251-63.

12. Kim SY, Kim JH, Jang YS, Choi JH, Park S, Hwang YI, et al. The basophil activation test is safe and useful for confirming drug-induced anaphylaxis. Allergy Asthma Immunol Res 2016;8:541-4.

13. Song JW, Jang YS, Jung MC, Kim JH, Choi JH, Park $\mathrm{S}$, et al. Levodropropizine-induced anaphylaxis: case series and literature review. Allergy Asthma Immunol Res 2017;9:278-80.

14. Simons FE, Ebisawa M, Sanchez-Borges M, Thong BY, Worm M, Tanno LK, et al. 2015 Update of the evidence base: World Allergy Organization anaphylaxis guidelines. World Allergy Organ J 2015;8:32.

15. Simons FE. Anaphylaxis pathogenesis and treatment. Allergy 2011;66 Suppl 95:31-4. 